\title{
Gene-environment interactions in severe intraventricular hemorrhage of preterm neonates
}

\author{
Laura R. Ment ${ }^{1,2}$, Ulrika Ådén ${ }^{3}$, Aiping Lin' ${ }^{1}$, Soo Hyun Kwon ${ }^{1}$, Murim Choi ${ }^{4}$, Mikko Hallman ${ }^{5}$, Richard P. Lifton ${ }^{4}$, Heping Zhang ${ }^{6}$ \\ and Charles R. Bauer'; for the Gene Targets for IVH Study Group
}

Intraventricular hemorrhage (IVH) of the preterm neonate is a complex developmental disorder, with contributions from both the environment and the genome. IVH, or hemorrhage into the germinal matrix of the developing brain with secondary periventricular infarction, occurs in that critical period of time before the 32nd to 33rd wk postconception and has been attributed to changes in cerebral blood flow to the immature germinal matrix microvasculature. Emerging data suggest that genes subserving coagulation, inflammatory, and vascular pathways and their interactions with environmental triggers may influence both the incidence and severity of cerebral injury and are the subject of this review. Polymorphisms in the Factor $V$ Leiden gene are associated with the atypical timing of $\mathrm{VH}$, suggesting an as yet unknown environmental trigger. The methylenetetrahydrofolate reductase (MTHFR) variants render neonates more vulnerable to cerebral injury in the presence of perinatal hypoxia. The present study demonstrates that the MTHFR 677C $>$ T polymorphism and low 5-min Apgar score additively increase the risk of IVH. Finally, review of published preclinical data suggests the stressors of delivery result in hemorrhage in the presence of mutations in collagen $4 \mathrm{~A} 1$, a major structural protein of the developing cerebral vasculature. Maternal genetics and fetal environment may also play a role.

C onverging data suggest that intraventricular hemorrhage (IVH) of the preterm neonate is a complex developmental disorder, with contributions from both the environment and the genome of the child. IVH, or hemorrhage into the germinal matrix (GM) of the developing brain with secondary periventricular infarction as shown in Figure 1, occurs in that critical period of time before the $32 \mathrm{nd}$ to $33 \mathrm{rd}$ wk postconception and has been attributed to changes in cerebral blood flow $(\mathrm{CBF})$ to the immature GM microvasculature. Inflammation, coagulation, and vascular factors may also play a role. The more severe grades are characterized by acute distension of the cerebral ventricular system with blood (grade 3) and IVH with parenchymal venous infarction (grade 4) (1). Mortality is high in infants with severe IVH, and one-quarter to one-half of surviving neonates develop cognitive disability and/or cerebral palsy $(2,3)$. In addition, $20 \%$ of nondisabled survivors suffer executive function and neuropsychiatric disorders, confirming that severe IVH is a major pediatric public health problem $(4,5)$.

Multiple lines of clinical data support the hypothesis that, similar to other preterm morbidities $(6,7)$, the etiology of IVH is multifactorial. First, despite the development of sophisticated neonatal intensive care strategies, IVH remains a significant problem of prematurity. Maternal transport, antenatal steroid administration, and improved resuscitation techniques have become standard of care in neonatal tertiary care units worldwide (8-11), but the incidence of severe IVH has remained $13-15 \%$ for almost 20 y $(8,12)$.

Although the incidence of IVH is inversely related to gestational age (GA) at birth, the risk period for hemorrhage is independent of GA $(13,14)$. The incidence of severe IVH is $7 \%$ for those born at $28 \mathrm{wk}$ and $26 \%$ for neonates born $4 \mathrm{wk}$ earlier, but the critical period for hemorrhage is the first $4-5 \mathrm{~d}$ of life for both the groups. These data suggest that either the transition to extrauterine life and/or the triggers to which the neonates are exposed contribute to hemorrhage, and both hypoxemia and inflammation have been implicated in severe IVH of the prematurely born.

Furthermore, both gender and twin studies support the hypothesis that IVH is a complex disorder. Preterm males are more likely than females to experience severe IVH (15). Similarly, studying 450 twin pairs, Bhandari et al. (16) reported that $41.3 \%$ of the variance in IVH risk is attributable to familial and environmental factors. Candidate gene studies implicate the inflammatory, coagulation, and vascular pathways, and recent data suggest that time of hemorrhage may play a role (17-19).

The purpose of this review is to examine preclinical and clinical data supporting the hypothesis that severe IVH is attributable in part to the interaction of the environment with the neonatal genome. Based on the pathogenesis of hemorrhage, factors mediating coagulation, inflammation, and vascular pathways have been chosen for review. 

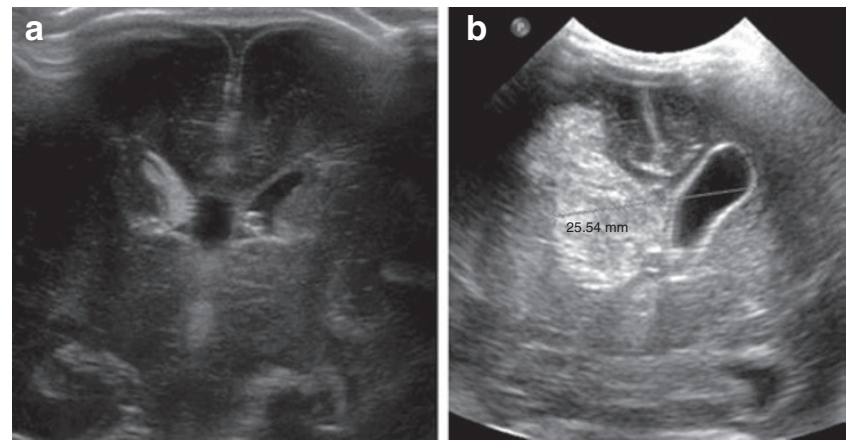

Figure 1. Severe intraventricular hemorrhage (IVH). Coronal ultrasounds at postnatal age (a) $1 \mathrm{~d}$ and (b) $4 \mathrm{~d}$ from a 28 -wk gestation neonate with $\mathrm{IVH}$. In a, blood is seen in the germinal matrix and filling the right lateral ventricle; at postnatal $d 4$, the ventricular system is dilated, and blood is seen both filling and distending the right lateral ventricle as well as in the parenchyma of the right hemisphere, consistent with grade $4 \mathrm{IVH}$.

\section{MODELS FOR INTERACTION BETWEEN THE ENVIRONMENT} AND THE GENOME

Although several investigators have hypothesized that IVH is secondary to the interaction of the environment and the genome (20), the mechanisms by which genetic predisposition and environmental exposures interact are just beginning to be described. Review of published literature interrogating vascular and environmental interactions suggest at least two different mechanisms. These include the impact of an environmental perturbation on a system harboring a known polymorphism, while the other stems from research addressing the influence of fetal programming on adult disorders postulating the role of epigenetics. Underlying both proposed mechanisms is the recognition that IVH is a developmental disorder occurring within a critical period of time, and both the polymorphisms and environment events we describe may result in very different or even unremarkable phenotypes in the term infant or older child.

In the first model, a gene confers vulnerability to environmental triggers (21). A common example is hypercarbia. Hypercarbia occurs in association with apneic events, lung disease, pneumothoraces, pulmonary hemorrhage, and other events. Preterm neonates exhibit a narrow range of carbon dioxide over which $\mathrm{CBF}$ remains constant. In response to hypercarbia, CBF to the immature GM microvasculature markedly increases and, in the presence of a vascular structural polymorphism, may result in hemorrhage (22). Although the same genetic variant that results in GM vascular instability may predispose the proband to subsequent neurovascular disorders, there is no reported transgenerational change in DNA.

In contrast, epigenetics refers to an alteration in gene function without changes in the underlying DNA sequence (21). Epigenetic mechanisms involve DNA methylation, histone density and posttranslational modifications, and the engagement of noncoding RNAs. Some alterations in the epigenome may be hereditable, resulting in transgenerational changes in genotype/phenotype correlations.

The programming of the epigenome is active during gestation, and epigenetic processes respond to environmental stimuli ranging from protein-calorie dietary restriction to hypoxia and fetal inflammatory exposures. Offspring of women experiencing preeclampsia, a putative marker for fetal hypoxia, have both hypertension and endothelial dysfunction during young adulthood (23). Similarly, in preclinical models, offspring of mothers exposed to protein-calorie deprivation during pregnancy also have vascular dysfunction, and these findings are reversed by maternal folate supplementation (24). Of note, folate deficiencies have also been associated with abnormalities in DNA methylation (25). Also, in preclinical studies, the endothelium-dependent abnormalities in the offspring of restricted diet pregnancies are ameliorated by the administration of histone deacetylase inhibitors, suggesting a transgenerational etiology for the findings (26).

Finally, the interactions between genetic polymorphisms, epigenetic mechanisms such as DNA methylation, and expression are complex. Emerging data suggest, however, that genetic variants regulate methylation, and methylation regulates gene expression. Thus, a genetic variant that creates or negates a DNA C-phosphate-G methylation site in the promoter region of a gene may significantly impact expression of that gene (27).

\section{PATHWAYS FOR ALTERATION OF THE IVH EPIGENOME}

Studies investigating mechanisms by which fetal or preterm exposures may alter the epigenome to promote or prevent IVH include the effects of hypoxia, inflammation, nutrition, and oxidative stress.

IVH has long been associated with hypoxic ischemic events, and putative inflammatory, excitotoxic, and apoptotic pathways are involved in the complex cascade following neonatal hypoxia ischemia. The hypoxia-inducible transcription factors (HIFs) are among the endogenous adaptive mechanisms modifying this cascade of events. HIFs are heterodimers of HIF- $\alpha$ and HIF- $\beta$ subunits that belong to a family of basic helix-loop-helix transcription factors. HIF-1 and HIF-2 are important regulators of oxygen-dependent gene transcription that modulate oxygen and metabolic supply during hypoxia. HIF target genes include those with vasoactive and vasoproliferative effects including vascular endothelial growth factor and inducible nitric oxide (NO) synthase. In a preclinical model of preterm hypoxia, HIF-1 $\alpha$ was prominently found in vascular endothelial and glial cells of the subventricular zone (28). Similarly, its target, vascular endothelial growth factor, mediates survival and tube stabilization of hypoxic brain microvascular endothelial cells in vitro (29). Finally, possibly acting via acetylation and methylation pathways, chronic hypoxia decreases global transcriptional activity (30). Thus, in preclinical fetal studies, chronic high-altitude hypoxia resulted in reduced histone acetylation and DNA methylation, fetal pulmonary arterial smooth muscle cell proliferation, vessel remodeling, and vascular dysfunction (31).

Likewise, biomarkers of inflammation such as interleukin $1 \beta(I L-1 \beta)$ and interleukin 6 (IL-6) activate the hypothalamicpituitary-adrenal axis, with putative long-term neurobehavioral sequelae (32). An example of such an epigenetic event is second-trimester maternal exposure to type A2/Singapore 


\section{Gene-environment interactions in IVH $\mid$ ReView}

influenza that significantly increased risk for adult psychiatric disorders (33).

Finally, as discussed above, preclinical studies suggest that, acting via metabolic, vascular, and stress-mediated pathways, maternal nutrition may have profound effects on the developing fetus $(24,26,34)$.

\section{PATHOPHYSIOLOGY OF IVH: PRECLINICAL CANDIDATES}

IVH begins in the GM, a site of active angiogenesis in the developing brain $(13,20)$ (Figure 2). Endothelial growth and sprouting are critical for angiogenesis, and the emerging blood-brain barrier is characterized by endothelial tight junctions, basement membrane proteins, perivascular pericytes, and glial endfeet. These processes are regulated by assorted growth factors, cell surface receptors, and intracellular signaling pathways.

Although preclinical studies postulate that it is the developmental stage of the GM microvessels that results in IVH, more recent studies suggest that mutations in one or more

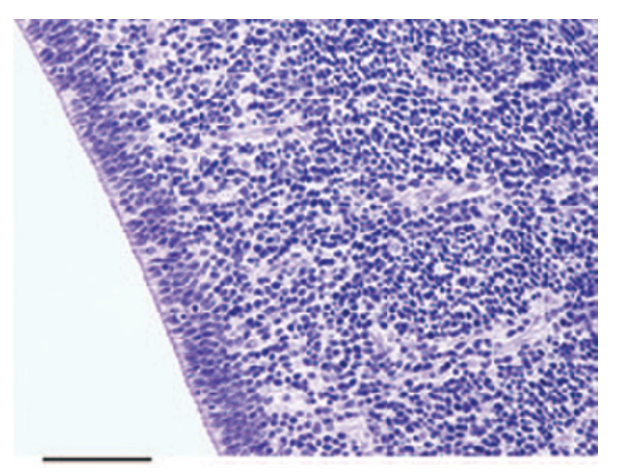

Figure 2. Germinal matrix, a densely cellular region located adjacent to the ependyma of the lateral ventricles. It is composed of immature neural precursor cells and vessels. Magnification 40x; scale bar $=1 \mathrm{~mm}$. (Figure courtesy of A. Huttner, Department of Pathology, Section of Neuropathology, Yale University School of Medicine, New Haven, CT.) microvascular proteins confer vulnerability to environmental triggers (Table 1). Mice with targeted mutations in the basement membrane proteins, fibronectin, laminin, collagen $4 \mathrm{~A} 1$ (COL4A1), and/or perlecan, demonstrate that all are necessary for vascular stabilization. Those with mutations in COL4A1 experience IVH following the stress accompanying vaginal delivery. In the murine model, these hemorrhages are preventable by surgical delivery, suggesting an interaction between an environmental trigger and the genome (35).

Similarly, although preclinical "risk factor" studies are not available, mice with mutations in activin receptor-like kinase 5 (Alk5) (36), alpha v integrins (37), annexin 7 (anx7) (38), cyclic adenosine 59-monophosphate response element-binding protein (39), death receptor 6 (DR6) (40), inhibitors of differentiation (Id) proteins 1 and 3 ( $I d 1, I d 3$, respectively) (41), or Tgfbr2 (36) also develop intracerebral hemorrhage mimicking Gr 4 IVH.

Transforming growth factor- $\beta$ (TGF- $\beta$ ) activation and signaling is essential for normal blood vessel growth and sprouting in developing brain, and av $\beta 8$ integrin mediates TGF- $\beta$ activation. Mouse embryos genetically null for integrin $\beta 8$ develop severe intracerebral hemorrhage beginning at embryonic day 11.5 (42). Similarly, TGF- $\beta$ signals are transduced by both TGF- $\beta$ type II and the TGF- $\beta$ type I receptors ( $T g f b r 2$ and Alk5, respectively), and in murine systems, selective deletion of Tgfbr2 or Alk5 in endothelial cells results in lethal intracerebral hemorrhage (36). In humans, mutations in Tgfbr2 and Alk5 cause Loeys-Dietz syndrome, characterized by multiple arterial aneurysms and dissections. Men with Alk5 mutations more commonly present with thoracic aortic aneurysm and die earlier than women with this disorder, suggesting a gender predilection for this polymorphism (43).

IVH is also found in mice with genetic alterations in the transcription factors such as $I d$ 1/3 (41), Friend leukemia integration $(39,44)$, and cyclic adenosine 59-monophosphate response element-binding protein (39). Id1 and Id3 prevent

Table 1. Candidate genes for IVH from preclinical studies

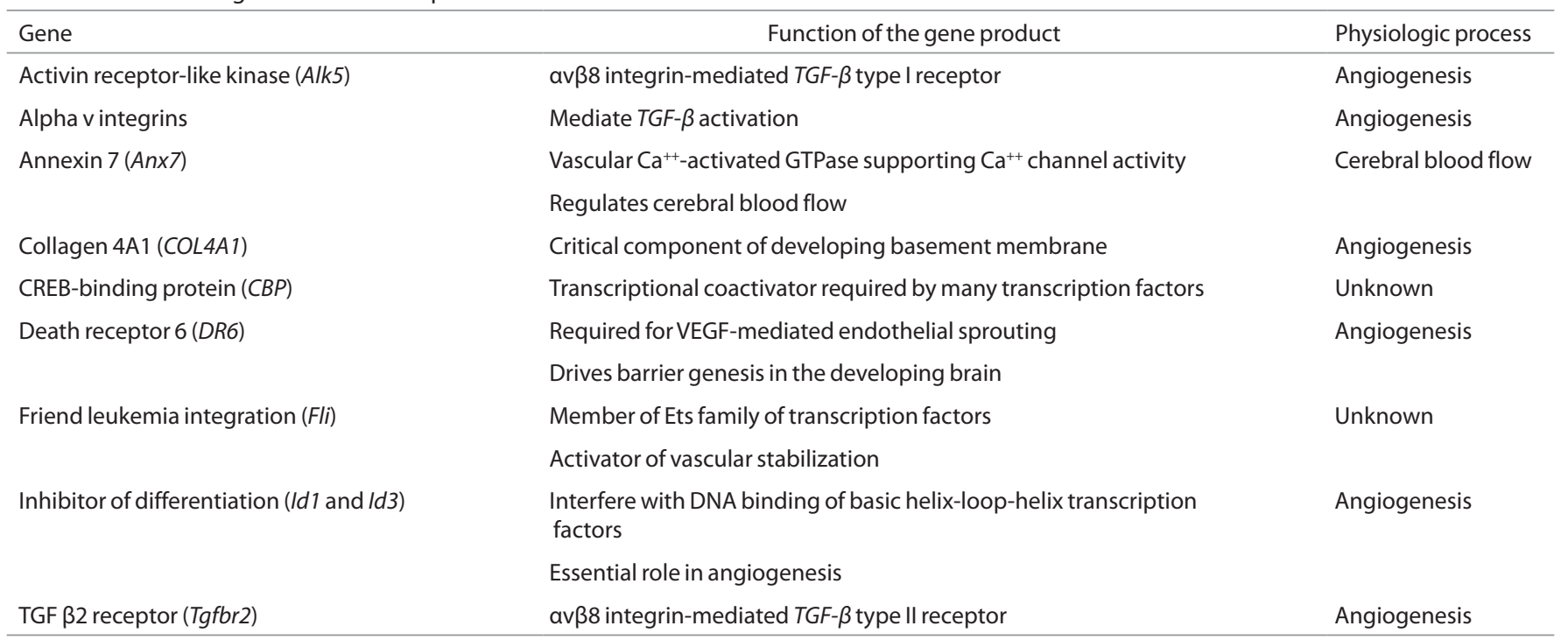

CREB, CAMP response binding element; IVH, intraventricular hemorrhage; TGF, transforming growth factor; VEGF, vascular endothelial growth factor. 
transcription by direct physical interaction with the basic helix-loop-helix transcription factors are expressed in cerebral endothelial cells and play an essential role in angiogenesis (45). The CREB-binding protein is a transcriptional coactivator, and Friend leukemia integration, which is a member of the Ets family of transcription factors, is a key regulator of vascular maturation (46). Finally, DR6 is required for vascular endothelial growth factor-mediated endothelial sprouting, is enriched in central nervous system vasculature, and drives barrier genesis in developing brain (38). Facing environmental triggers including hypoxia, hypercarbia, and hypertension, polymorphisms in some or all of these factors may result in hemorrhage.

Likewise, changes in CBF may contribute to hemorrhage. Autoregulation relies on smooth muscle cells, pericytes, and proteins ranging from $\mathrm{Ca}^{++}$and $\mathrm{K}^{+}$channels, phospholipase A1, arachidonic acid, and adenosine to $\mathrm{NO}$ and cytokines among others (20). Notably, mice with mutations in Anx7, a gene encoding a $\mathrm{Ca}^{++}$-activated GTPase supporting $\mathrm{Ca}^{++}$channel activity, experience IVH, suggesting that, in the presence of environmental perturbations, mutations in genes controlling CBF may contribute to hemorrhage (38).

\section{EVIDENCE FOR GENE-BY-ENVIRONMENT INTERACTIONS: CLINICAL STUDIES OF SEVERE HEMORRHAGE}

Studies in preterm neonates have implicated an array of candidate genes spanning the coagulation, inflammatory, and vascular pathways. For this review, we compare and contrast the studies of Harteman et al. (17), Ryckman et al. (18), and Baier (19) and our Gene Targets study. As shown in Table 2, the numbers of subjects, their birth weight (BW), and GA as well as their racial and ethnic backgrounds were quite varied, as were the years in which they were born and, presumptively, the neonatal intensive care the neonates received (17).

\section{Coagulation Candidates}

Coagulation factors have long been considered candidate genes for IVH, both because of the pathophysiology of hemorrhage and because of their putative role in perinatal stroke (47) (Table 3). The most widely studied include the factor V Leiden (F5) variant, polymorphisms of the methylenetetrahydrofolate reductase (MTHFR) gene, and the prothrombin 20210G>A variant (F2).
The contribution of the F5 polymorphism to IVH has been interrogated in different populations. A point mutation results in replacement of amino acid 506 arginine to glutamine in an activated protein $\mathrm{C}$ cleavage site. Activated protein $\mathrm{C}$ cleaves the peptide bonds in activated F5, resulting in inhibition of the coagulation pathway, and the variant presents with hypercoagulability. Gopel et al. (48) reported that this polymorphism was associated with Gr 1-2 IVH but protected against parenchymal hemorrhage. In contrast, Ryckman et al. (18) found that the heterozygous genotype was associated with Gr 1-2, but not Gr 3-4, IVH.

Similarly, Harteman et al. (17) studied 17 preterm neonates with atypical presentation of Gr 4 IVH; atypical hemorrhages were defined as occurring in the absence of provoking clinical factors more than $96 \mathrm{~h}$ following birth (Figure 3). Seven of 17 were heterozygous for the F5 variant, suggesting an association between this hypercoagulable state and atypical hemorrhage. Recent studies suggest that related or unrelated thrombophilia in the mothers increase the risk of perinatal stroke (47), and six of seven mothers of F5 infants harbored this variant. Although the incidence of variant status in the patients in this study is significantly higher than that for the Dutch population, no data are provided for neonates with typical onset Gr 4 hemorrhage.

Finally, Baier (19) found no association between F5 and IVH in his cohort of 99 mostly African-American extremely-lowBW neonates.

Of note, IVH is more common in male preterm neonates, and although no gender-by-F5 data are currently available for neonates with IVH, males with the F5 polymorphism are more likely than F5 females to experience recurrence of peripheral venous thrombosis, suggesting a possible gender effect for this mutation (49).

A second leading candidate is MTHFR. MTHFR catalyzes the reduction of 5,10-methylenetrahydrofolate to 5-methyltetrahydrofolate, which is necessary for the conversion of homocysteine to methionine. Hyperhomocysteinemia is associated with polymorphisms at -677 and -1298, especially at the 677 TT variant, and results in endothelial cell injury and alterations in coagulation including stroke, thrombosis, migraine, and vascular disorders (50,51). Hyperhomocysteinemia is exacerbated under conditions of low folate, and this increases the susceptibility to experimental brain damage.

Table 2. Comparison of the selected study populations

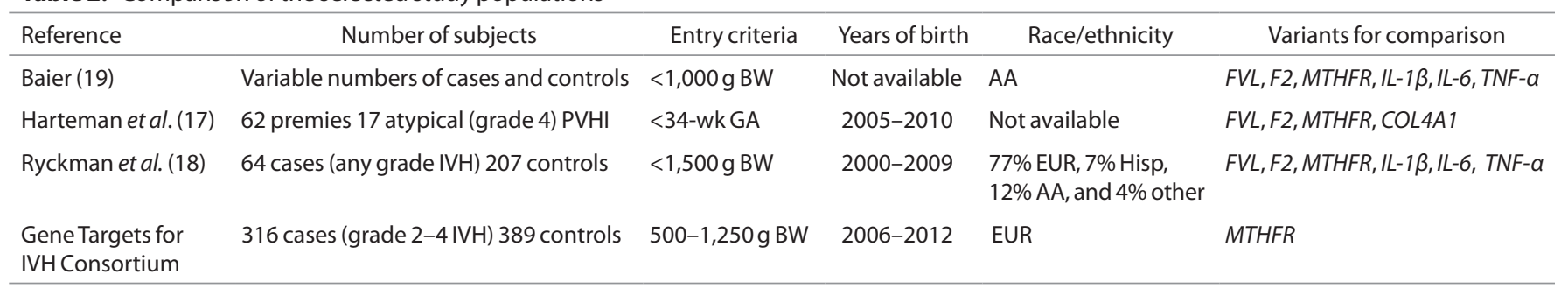

AA, African American; BW, birth weight; COL4A1, collagen 4A1; EUR, Europeon; FVL, factorV Leiden; GA, gestational age; Hisp, Hispanic; IL-13, interleukin 13; IL-6, interleukin 6; IVH, intraventricular hemorrhage; MTHFR, methylenetetrahydrofolate reductase; TNF, tumor necrosis factor. 


\section{Gene-environment interactions in IVH $\mid$ ReView}

Table 3. Coagulation, inflammation, and vascular candidate genes for IVH from clinical studies

\begin{tabular}{|c|c|c|}
\hline Gene name, symbol, SNP & Change in function/structure & Reported environment-gene interactions \\
\hline \multicolumn{3}{|l|}{ Coagulation } \\
\hline Factor V Leiden (F5) 1601G>A & $\begin{array}{l}\text { Resistance of FV to inactivation by activated } \\
\text { protein } C \text { and hypercoagulability }\end{array}$ & Associated with atypical timing of IVH \\
\hline $\begin{array}{l}\text { Methylenetetrahydrofolate reductase (MTHFR) } \\
677 C>T ; 1298 A>C\end{array}$ & $\begin{array}{l}\text { Decreased conversion of homocysteine } \\
\text { to methionine and homocysteine toxic to } \\
\text { endothelial cells }\end{array}$ & $\begin{array}{l}\text { Associated with atypical timing of IVH } \\
\text { interactions with maternal diet and folate } \\
\text { interactions with perinatal hypoxia }\end{array}$ \\
\hline \multicolumn{3}{|l|}{ Inflammation } \\
\hline Interleukin $1 \beta(I L-1 \beta) 87-511 T>C$ 87-31C>T & $\begin{array}{l}\text { Impaired activation of the HPA axis and } \\
\text { altered CNS inflammatory response }\end{array}$ & $\begin{array}{l}\text { Environmental interaction with } \\
I L-1 \beta-511 \mathrm{~T} \text { allele and ureaplasma urealytica } \\
\text { colonization for } \mathrm{PVL} \text { but not for severe IVH }\end{array}$ \\
\hline Interleukin $6(I L-6)$ 116-121C>G & Altered CNS inflammatory response & \\
\hline Endothelial nitric oxide synthase (eNOS) 786T >C & Decreased endogenous nitric oxide & \\
\hline Superoxide dismutase 3(SOD3) rs8192287 (-416TG>C) & Impaired oxidative stress response & \\
\hline
\end{tabular}

CNS, central nervous system; HPA, hypothalamic-pituitary-adrenal; IL-1 $\beta$, interleukin 1 1 ; IVH, intraventricular hemorrhage; PVL, periventricular leukomalacia; SNP, single-nucleotide polymorphism; TNF, tumor necrosis factor.
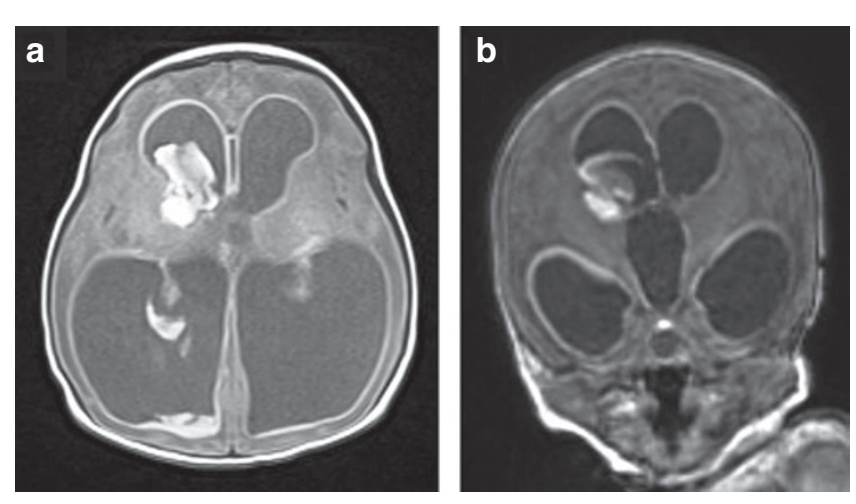

Figure 3. Atypical intraventricular hemorrhage (IVH). (a) Axial and (b) coronal images of a 1-d-old 34-wk gestation infant with the atypical (fetal) onset of germinal matrix and IVH. Note the hemorrhage into the right germinal matrix, intraventricular blood, and ventriculomegaly characteristic of posthemorrhagic hydrocephalus. (Figure courtesy of C.C. Duncan, Department of Neurosurgery, Yale University School of Medicine, New Haven, CT.)

MTHFR may additionally play an important role in neonatal brain injury. Studying the prevalence of the $677 \mathrm{C}>\mathrm{T}$ variant in 11 neonates with hypoxic ischemic encephalopathy and their mothers, Dodelson de Kremer and Grosso (52) found that compared with a $68 \%$ incidence of the $\mathrm{T}$ allele in the control population, all 11 carried this polymorphism. The variant was more common in mothers of affected offspring and was associated with an increase in maternal homocysteine, suggesting a profound alteration in the fetal environment. The mothers in this study exhibited poor nutrition, and the authors postulated that underlying folate deficiency during pregnancy may have exacerbated the influence of hypoxic injury in neonates harboring the MTHFR variant.
More recently, Harteman et al. (53) evaluated 118 infants with hypoxic-ischemic encephalopathy and reported that the magnetic resonance imaging white matter/watershed pattern of injury was associated with MTHFR CT or TT 677 polymorphisms and plasma homocysteine levels in the upper quartile. In this study, neonatal MTHFR polymorphisms were not associated with homocysteine levels, consistent with the findings of other observers (54). Of interest, Molloy et al. (55) demonstrated that maternal homocysteine levels are the best predictors of fetal values, emphasizing the importance of the fetal environment.

Acute hypoxia ischemia results in thrombosis in subjects lacking known polymorphisms (56), and hypoxia exacerbates the effect of a folate-deficient diet on homocysteine metabolism $(57,58)$. Blaise et al. (59) demonstrated that in rat pups exposed prenatally to diets deficient in vitamins B12, B2, folate, and choline through weaning, hypoxia increased plasma homocysteine levels. MTHFR activity was attenuated by hypoxia. Furthermore, hypoxia enhanced the deficiency-induced drop of the S-adenosylmethionine/S-adenosylhomocysteine ratio, known to influence DNA methylation and gene expression. Taken together, these data suggest the potential interaction between maternal and fetal MTHFR polymorphisms, folate, and hypoxic-ischemic injury to preterm brain.

Coinheritance of more than one thrombophilia variant is associated with a greater risk of thrombotic events than with a single polymorphism. Thus, in addition to assessing F5, Harteman et al. investigated the $677 \mathrm{C}>\mathrm{T}$ and $1298 \mathrm{~A}>\mathrm{C}$ polymorphisms in 16 of 17 preterms with atypical periventricular hemorrhagic infarction PVHI (Table 3). Six had the -677 T allele, 4 had the $-1298 \mathrm{C}$ variant, and 4 were compound heterozygous suggesting that 14 of 16 neonates had potentially deleterious polymorphisms. In contrast, 
there were no significant differences in genotypes for case and control neonates studied by Ryckman et al. or Baier.

Based on our previous work demonstrating a difference in the MTHFR -1298C polymorphism between severe IVH cases and controls and the putative role of hypoxia in MTHFRmediated brain injury (60), we tested the hypothesis that there would be a gene-by-environment interaction for these two factors. For this preliminary analysis, we interrogated only the MTHFR 1298A>C variant in the Gene Targets for IVH Consortium (NS053865) database. (Institutional review board approval was obtained from all participating institutions.) This consortium has both environmental data and DNA from over 1,400 inborn appropriate-for-GA preterm neonates with antenatal steroid administration, BW 500-1,250 g, and centrally read cranial ultrasounds. Only the 705 European subjects were included in this analysis to avoid racial admixture.

Three hundred sixteen infants had Gr 2-4 IVH; 389 neonates had no evidence for IVH. Cases had lower BW and GA than controls, and their mothers were more likely to have experienced chorioamnionitis and multiple gestation pregnancies (Table 4). In contrast, case mothers had less preeclampsia and fewer cesarean section deliveries. Cases were more likely to have 5-min Apgar scores $<3$ and require intubation for delivery room resuscitation.

An analysis of generalized linear mixed model with site as a random effect and all significant variables from Table 4 as fixed effects was performed to measure the relationship between IVH status and those independent variables including GA, preeclampsia, clinical chorioamnionitis, complete antenatal steroid administration within $7 \mathrm{~d}$ before delivery, multiple gestation, cesarean section, Apgar $1 \mathrm{~min}<3$, Apgar $5 \mathrm{~min}<3$, intubation for resuscitation, and the MTHFR 1298A $>$ C variant. Similar to previous reports (for review, see ref. (61)), this analysis demonstrated that increasing GA, cesarean delivery, and a complete course of antenatal steroid administration in the week before delivery were protective for Gr 2-4 IVH; in contrast, multiple gestation pregnancy and chorioamnionitis were independent and important risk factors for $\mathrm{Gr}$ 2-4 IVH. In addition, the MTHFR variant and the interaction term Apgar $_{5}<3$-by-MTHFR allele) were independent and important predictors of Gr 2-4 IVH in our population (Table 5).

The F2 variant is the last leading coagulation candidate we are discussing. It results in increased thrombin and secondary thrombosis, and in the studies of Baier, Harteman et al., and Ryckman et al., it was not associated with a risk for IVH.

\section{Inflammatory Factors}

Cytokines are also postulated to play a role in perinatal brain injury, and both Ryckman et al. and Baier explored the role of interleukins in preterm IVH. Hypoxia results in the loss of blood-brain barrier function and impaired tight junction protein synthesis (62), permitting cytokines from the peripheral circulation to directly enter preterm brain. In addition, cytokines secreted by cells of the immune system may also be synthesized by central nervous system glial to act as signal transmitters in the developing brain (63).
Table 4. Gene Targets for IVH Consortium study subjects

\begin{tabular}{|c|c|c|c|}
\hline & EUR Gr 2-4 IVH & Controls & $P$ value \\
\hline Number of subjects & 316 & 389 & \\
\hline $\begin{array}{l}\text { Birth weight in grams } \\
(N, S D)\end{array}$ & $821.4(316,184.1)$ & $864.3(389,174.0)$ & $<0.0001$ \\
\hline GA in weeks $(N, S D)$ & $25.7(314,1.5)$ & $26.5(388,1.5)$ & $<0.0001$ \\
\hline Male subjects (\%) & 187/316 (59.2\%) & 231/389 (59.4\%) & 1 \\
\hline \multicolumn{4}{|l|}{ IVH status } \\
\hline Grade 2 & 92 & & \\
\hline Grade 3 & 95 & & \\
\hline Grade 4 & 129 & & \\
\hline \multicolumn{4}{|l|}{ Maternal variables } \\
\hline $\begin{array}{l}\text { Maternal prenatal } \\
\text { visit (\%) }\end{array}$ & $307 / 314(97.8 \%)$ & $384 / 389(98.7 \%)$ & 0.3887 \\
\hline Preeclampsia (\%) & 35/314 (11.1\%) & $91 / 388(23.5 \%)$ & $<0.0001$ \\
\hline $\begin{array}{l}\text { Clinical } \\
\text { chorioamnionitis (\%) }\end{array}$ & $95 / 315(30.2 \%)$ & 69/389 (17.7\%) & 0.0001 \\
\hline $\begin{array}{l}\text { Any ANS within } 7 d \\
\text { before delivery (\%) }\end{array}$ & 277/315 (87.9\%) & 336/388 (86.6\%) & 0.6504 \\
\hline $\begin{array}{l}\text { Complete ANS } \\
\text { within } 7 \mathrm{~d}(\%)\end{array}$ & 176/316 (55.7\%) & 260/389 (66.8\%) & 0.003 \\
\hline $\begin{array}{l}\text { Multiple gestation } \\
\text { (\%) }\end{array}$ & 116/316 (36.7\%) & $90 / 386(23.3 \%)$ & 0.0001 \\
\hline Cesarean section & 187/316 (59.2\%) & 281/388 (72.4\%) & 0.0002 \\
\hline \multicolumn{4}{|l|}{ Delivery room variables } \\
\hline Apgar 1 min <3 (\%) & $99 / 314(31.5 \%)$ & $89 / 388(22.9 \%)$ & 0.0128 \\
\hline Apgar $5 \min <3(\%)$ & 28/315 (8.9\%) & 14/388 (3.6\%) & 0.0038 \\
\hline $\begin{array}{l}\text { Intubation for } \\
\text { resuscitation }\end{array}$ & 244/295 (82.7\%) & 243/351 (69.2\%) & $<0.0001$ \\
\hline $\begin{array}{l}\text { Epinephrine for } \\
\text { resuscitation }\end{array}$ & $10 / 230(4.3 \%)$ & $5 / 215(2.3 \%)$ & 0.2977 \\
\hline \multicolumn{4}{|l|}{ MTHFR polymorphisms } \\
\hline $\begin{array}{l}-1298 \text { CC or CA } \\
\text { genotype }\end{array}$ & 176/316(55.7\%) & $176 / 389(45.2 \%)$ & 0.006 \\
\hline
\end{tabular}

$I L-1 \beta$ is the major cytokine involved in activation of the hypothalamic-pituitary-adrenal axis (31). In addition, although the exact mechanisms by which $I L-1 \beta$ is involved in hypoxiaischemia, IVH, and perinatal brain injury remain unknown, $I L-1 \beta$ has been implicated in the progression of injury in the developing brain (64). Of importance to the understanding of critical period injuries such as IVH, expression of $I L-1 \beta$ is both developmentally and regionally regulated in the brains of typically developing fetuses and neonates (65). Similarly, in response to hypoxic-ischemic injury, $I L-1 \beta$ differentially increases across the brain, suggesting regional vulnerability to cytokine-mediated injury.

Preclinical studies demonstrate that perinatal $I L-1 \beta$ exposure induces acute white matter injury with subsequent ventriculomegaly, loss of mature oligodendrocytes, impaired myelination, decreased myelin basic protein, and axonal and dendritic injury (66). In addition, acting via the cyclooxygenase-2 (COX-2) 


\section{Gene-environment interactions in IVH $\quad$ ReView}

Table 5. Analysis of generalized linear mixed model with random effects from the Gene Targets for IVH Consortium

\begin{tabular}{|c|c|c|c|c|}
\hline Effect & Odds ratio & $95 \% \mathrm{C}$ & dence limits & $P$ value \\
\hline GA & 0.707 & 0.629 & 0.794 & $<0.001$ \\
\hline Chorioamnionitis & 1.563 & 1.049 & 2.330 & 0.028 \\
\hline Cesarean delivery & 0.569 & 0.394 & 0.820 & 0.003 \\
\hline Complete course ANS & 0.663 & 0.471 & 0.935 & 0.019 \\
\hline Multiple gestation & 2.445 & 1.685 & 3.576 & $<0.001$ \\
\hline MTHFR & 1.427 & 1.022 & 1.992 & 0.037 \\
\hline Apgar $_{5}<3$-by-MTHFR & 3.210 & 1.008 & 10.225 & 0.048 \\
\hline
\end{tabular}

pathway (67), perinatal bacterial infection significantly increases $I L-1 \beta, I L-6$, and corticosterone production in rat pups a few hours after infection, suggesting involvement of both the central inflammatory and hypothalamic-pituitary-adrenal pathways (68). Such perinatal immune activation has been associated not only with change in behavior in neonatal animals but also disrupted avoidance learning in male, but not female subjects in adulthood (69). Taken together, these data suggest that early $I L-1 \beta$-mediated immune activation results in long-term changes in both structure and function in developing brain.

When Baier evaluated the role of $I L-1 \beta 511 \mathrm{C}>\mathrm{T}$ polymorphisms in 215 ventilated very-low-BW infants, the $I L-1 \beta-511$ $\mathrm{T}$ allele was associated with increased risk for IVH. One-third of infants with the T allele experienced IVH, compared with $14 \%$ with the $\mathrm{C}$ allele. There was also a significant difference in Gr 3-4 IVH between the groups. Periventricular leukomalacia was also increased, mainly in those infants with the CT genotype. Because of the association of chorioamnionitis and periventricular leukomalacia, Baier interrogated the interaction of ureaplasma urealyticum colonization and $I L-1 \beta 511 \mathrm{~T}$ allele on the incidence and severity of both IVH and periventricular leukomalacia. Consistent with the report of Leviton et al. (70), there was no interaction for these triggers in neonates with IVH. In contrast, infants with both the 511T allele and ureaplasma urealyticum were at greater risk of periventricular leukomalacia than infants with one or none of these triggers, suggesting a gene-by-environment interaction.

Ryckman et al. validated this result by finding that the $I L-1 \beta$-31 C allele was associated with an increased risk for hemorrhage. The $\mathrm{C}$ allele of $I L-1 \beta-31$ is in strong linkage disequilibrium with the $\mathrm{T}$ allele of $I L-1 \beta-511$, and both increase the production of $I L-1 \beta$ in vivo (71).

Similarly, IL-6 has also been implicated in injury in developing brain $(65,72)$ and has also been shown to activate the hypothalamic-pituitary-adrenal axis (73). Thus, IL-6 is also believed to be a strong candidate to modify risk for preterm brain injury. Harding et al. (74) reported that in 151 preterm neonates, the CC genotype of IL-6-174 significantly increased the risk for IVH and neurodevelopmental disability at $2 \mathrm{y}$ of age. In contrast, interrogating the same polymorphism, neither Baier nor Ryckman et al. found any relationship between IL-6 and IVH in the prematurely born.
Tumor necrosis factor (TNF)- $\alpha$ plays a pivotal role in the acute-phase proinflammatory cytokine cascade and is also postulated to be a central mediator of brain injury in the prematurely born (75). The TNF- $\alpha$ gene is polymorphic, and there are numerous polymorphisms in the promoter region. Studying 178 ventilated very-low-BW infants, Adcock et al. reported that the -308 A allele in the TNF- $\alpha$ promoter region was associated with IVH in preterm neonates (75). Baier also found that in infants with the TNF- $\alpha-308$ A allele, the incidence of IVH was $40 \%$ as compared with $24 \%$ in those with GG (19). However, Ryckman et al. found no association between this polymorphism and IVH in her population.

\section{Vascular Genes}

Proteins both contributing to the integrity of the developing central nervous system vasculature and those mediating CBF are excellent targets for IVH. COL4A1 encodes type IV collagen alpha chain 1 . This is one of six alpha chains that contribute to type IV collagen, a principal component of basement membranes ubiquitously expressed during development. Truncating mutations in murine Col4A1 result in cerebral hemorrhage in both neonatal and adult mice, and mutations have been reported in infants with congenital porencephaly, fetal IVH, and adults with cerebral small vessel disease $(35,76)$. More recently, mutations have also been reported in preterm neonates with IVH $(77,78)$. Studying 41 preterm infants with IVH, Bilguvar et al. (79) identified a rare heterozygous duplication within a highly conserved residue in COL4A1 in dizygotic twins with Gr 4 IVH.

In addition to inhibiting platelet and leukocyte adhesion to vascular endothelium, NO promotes cerebral vasodilatation (80). Several allelic variants have been reported in promoter of the endothelial NO synthase gene, which have been associated with decreased endothelial NO synthase activity and reductions in NO. Investigating 124 African-American preterm neonates, Vannemreddy et al. (81) reported the association of the endothelial NO synthase gene promoter polymorphism $786 \mathrm{~T}>\mathrm{C}$ with $\mathrm{IVH}$, suggesting that the vascular actions of endothelial NO synthase are critical for the prevention of hemorrhage in the developing brain.

Finally, oxidative stress may also play a role, and Poggi et al. (82) reported that the rs8192287 superoxide dismutase 3 polymorphism is an independent protective factor for IVH in 152 neonates of $<28 \mathrm{wk} \mathrm{GA}$. Although the mechanism is not yet known, Poggi et al. postulates protection of the cerebral microvessels against oxidative injury.

\section{IMPLICATIONS OF THE SCIENCE: FUTURE APPROACHES FOR DECREASING THE INCIDENCE OF IVH}

Further understanding of the genetic contributions to IVH, including genome-wide association studies and/or wholeexome sequencing data, will permit the rationale design of randomized clinical trials. These might include delivery mode trials for fetuses harboring vascular structural polymorphisms and strategies to lower homocysteine in mothers and/or neonates with MTHFR variants. Equally important avenues of molecular 
investigation might include inhibiting disease-causing pathways, such as the proposed use of rapamycin for subependymal giant cell astrocytomas in children with tuberous sclerosis (83); upregulating affected proteins from homologous genes as in models of spinal muscular atrophy (84); or counteracting the downstream effects of a deficient protein, such as the proposed use of insulin-like growth factor 1 in children with Duchenne's dystrophy (for review, see ref. (85)).

Available preclinical genetic studies and clinical candidate gene reports suggest that IVH may be attributable to numerous genes with small effect sizes and the environmental factors that interact with them. Because these common variants have small-to-moderate effects on disease risk, individual risk variants are neither necessary nor sufficient to produce disease, and there are consequently individuals with disease without risk variants and, conversely, individuals without disease who harbor risk variants. A hope is that identification of genes and pathways underlying IVH will permit the development of prenatal diagnostics and/or preventive therapeutics. To address these issues, a large-scale neonatal genomic medicine network must be developed with infrastructural capacity to both host an accessible database of sequence variants and their phenotypic associations and support a framework for defining and cataloging clinically actionable variants (86).

\section{CONCLUSION}

If a major focus of perinatal care is to prevent brain injury and abnormal development (87), then physicians and scientists must better understand those factors that contribute to severe IVH in the prematurely born. Emerging data suggest an important role of genes subserving coagulation, inflammatory, and vascular pathways, and interactions with maternal and neonatal environmental triggers may influence both the incidence and severity of cerebral injury and have long-term implications.

\section{ACKNOWLEDGMENTS}

We are indebted to our medical, nursing, and research colleagues and the infants and their parents who agreed to take part in this study. We are grateful to Deborah Hirtz for scientific expertise, Linda de Vries and Praveen Ballabh for reviewing the manuscript and making important scientific contributions, Jill Maller-Kesselman for study management, Carol Nelson-Williams for scientific expertise, Walter C. Allan for ultrasound expertise, and Karen C. Schneider for editorial expertise and assistance.

\section{STATEMENT OF FINANCIAL SUPPORT}

This work was supported by the National Institutes of Health, Bethesda, MD, NS053865. H.Z. was also partially supported by R01 DA016750-09.

Disclosure: None of the authors have any disclosures of financial ties to products in the study or potential/perceived conflicts of interest.

\section{REFERENCES}

1. Papile LA, Burstein J, Burstein R, Koffler H. Incidence and evolution of subependymal and intraventricular hemorrhage: a study of infants with birth weights less than 1,500 gm. J Pediatr 1978;92:529-34.

2. Nongena P, Ederies A, Azzopardi DV, Edwards AD. Confidence in the prediction of neurodevelopmental outcome by cranial ultrasound and MRI in preterm infants. Arch Dis Child Fetal Neonatal Ed 2010;95:F388-90.

3. Beaino G, Khoshnood B, Kaminski M, et al.; EPIPAGE Study Group. Predictors of cerebral palsy in very preterm infants: the EPIPAGE prospective population-based cohort study. Dev Med Child Neurol 2010;52:e119-25.
4. Luu TM, Ment L, Allan W, Schneider K, Vohr BR. Executive and memory function in adolescents born very preterm. Pediatrics 2011;127:e639-46.

5. Whitaker AH, Feldman JF, Lorenz JM, et al. Neonatal head ultrasound abnormalities in preterm infants and adolescent psychiatric disorders. Arch Gen Psychiatry 2011;68:742-52.

6. Hallman M. Premature birth and diseases in premature infants: common genetic background? J Matern Fetal Neonatal Med 2012;25 (Suppl 1):21-4.

7. Mohamed S, Schaa K, Cooper ME, et al. Genetic contributions to the development of retinopathy of prematurity. Pediatr Res 2009;65:193-7.

8. Stoll BJ, Hansen NI, Bell EF, et al.; Eunice Kennedy Shriver National Institute of Child Health and Human Development Neonatal Research Network. Neonatal outcomes of extremely preterm infants from the NICHD Neonatal Research Network. Pediatrics 2010;126:443-56.

9. Mohamed MA, Aly H. Transport of premature infants is associated with increased risk for intraventricular haemorrhage. Arch Dis Child Fetal Neonatal Ed 2010;95:F403-7.

10. Perlman JM, Wyllie J, Kattwinkel J, et al.; Neonatal Resuscitation Chapter Collaborators. Part 11: Neonatal resuscitation: 2010 International Consensus on Cardiopulmonary Resuscitation and Emergency Cardiovascular Care Science With Treatment Recommendations. Circulation 2010;122(Suppl 2):S516-38.

11. Sweet DG, Carnielli V, Greisen G, et al.; European Association of Perinatal Medicine. European consensus guidelines on the management of neonatal respiratory distress syndrome in preterm infants - 2010 update. Neonatology 2010;97:402-17.

12. Hack M, Wright LL, Shankaran S, et al. Very-low-birth-weight outcomes of the National Institute of Child Health and Human Development Neonatal Network, November 1989 to October 1990. Am J Obstet Gynecol 1995;172(2 Pt 1):457-64.

13. Volpe JJ. Brain injury in premature infants: a complex amalgam of destructive and developmental disturbances. Lancet Neurol 2009;8:110-24.

14. Shalak L, Perlman JM. Hemorrhagic-ischemic cerebral injury in the preterm infant: current concepts. Clin Perinatol 2002;29:745-63.

15. Kent AL, Wright IM, Abdel-Latif ME; New South Wales and Australian Capital Territory Neonatal Intensive Care Units Audit Group. Mortality and adverse neurologic outcomes are greater in preterm male infants. Pediatrics 2012;129:124-31.

16. Bhandari V, Bizzarro MJ, Shetty A, et al.; Neonatal Genetics Study Group. Familial and genetic susceptibility to major neonatal morbidities in preterm twins. Pediatrics 2006;117:1901-6.

17. Harteman JC, Groenendaal F, van Haastert IC, et al. Atypical timing and presentation of periventricular haemorrhagic infarction in preterm infants: the role of thrombophilia. Dev Med Child Neurol 2012;54:140-7.

18. Ryckman KK, Dagle JM, Kelsey K, Momany AM, Murray JC. Replication of genetic associations in the inflammation, complement, and coagulation pathways with intraventricular hemorrhage in LBW preterm neonates. Pediatr Res 2011;70:90-5.

19. Baier RJ. Genetics of perinatal brain injury in the preterm infant. Front Biosci 2006;11:1371-87.

20. Ballabh P. Intraventricular hemorrhage in premature infants: mechanism of disease. Pediatr Res 2010;67:1-8.

21. Bird A. Perceptions of epigenetics. Nature 2007;447:396-8.

22. Hambleton G, Wigglesworth JS. Origin of intraventricular haemorrhage in the preterm infant. Arch Dis Child 1976;51:651-9.

23. Davis EF, Newton L, Lewandowski AJ, et al. Pre-eclampsia and offspring cardiovascular health: mechanistic insights from experimental studies. Clin Sci 2012;123:53-72.

24. Torrens C, Brawley L, Anthony FW, et al. Folate supplementation during pregnancy improves offspring cardiovascular dysfunction induced by protein restriction. Hypertension 2006;47:982-7.

25. Shirodkar AV, Marsden PA. Epigenetics in cardiovascular disease. Curr Opin Cardiol 2011;26:209-15.

26. Rexhaj E, Bloch J, Jayet PY, et al. Fetal programming of pulmonary vascular dysfunction in mice: role of epigenetic mechanisms. Am J Physiol Heart Circ Physiol 2011;301:H247-52. 


\section{Gene-environment interactions in IVH $\quad$ ReView}

27. van Eijk KR, de Jong S, Boks MP, et al. Genetic analysis of DNA methylation and gene expression levels in whole blood of healthy human subjects. BMC Genomics 2012;13:636.

28. Trollmann R, Gassmann M. The role of hypoxia-inducible transcription factors in the hypoxic neonatal brain. Brain Dev 2009;31:503-9.

29. Chow J, Ogunshola O, Fan SY, Li Y, Ment LR, Madri JA. Astrocyte-derived VEGF mediates survival and tube stabilization of hypoxic brain microvascular endothelial cells in vitro. Brain Res Dev Brain Res 2001;130:123-32.

30. Fish JE, Yan MS, Matouk CC, et al. Hypoxic repression of endothelial nitric-oxide synthase transcription is coupled with eviction of promoter histones. J Biol Chem 2010;285:810-26.

31. Yang Q, Lu Z, Ramchandran R, Longo LD, Raj JU. Pulmonary artery smooth muscle cell proliferation and migration in fetal lambs acclimatized to high-altitude long-term hypoxia: role of histone acetylation. Am J Physiol Lung Cell Mol Physiol 2012;303:L1001-10.

32. Gadek-Michalska A, Tadeusz J, Rachwalska P, Spyrka J, Bugajski J. Brain nitric oxide synthases in the interleukin-1ß-induced activation of hypothalamic-pituitary-adrenal axis. Pharmacol Rep 2012;64:1455-65.

33. Machón RA, Mednick SA, Huttunen MO. Adult major affective disorder after prenatal exposure to an influenza epidemic. Arch Gen Psychiatry 1997;54:322-8.

34. Vieira-Filho LD, Lara LS, Silva PA, et al. Placental oxidative stress in malnourished rats and changes in kidney proximal tubule sodium ATPases in offspring. Clin Exp Pharmacol Physiol 2009;36:1157-63.

35. Gould DB, Phalan FC, van Mil SE, et al. Role of COL4A1 in small-vessel disease and hemorrhagic stroke. N Engl J Med 2006;354:1489-96.

36. Nguyen HL, Lee YJ, Shin J, et al. TGF- $ß$ signaling in endothelial cells, but not neuroepithelial cells, is essential for cerebral vascular development. Lab Invest 2011;91:1554-63.

37. McCarty JH, Lacy-Hulbert A, Charest A, et al. Selective ablation of alphav integrins in the central nervous system leads to cerebral hemorrhage, seizures, axonal degeneration and premature death. Development 2005; 132:165-76.

38. Srivastava M, Atwater I, Glasman M, et al. Defects in inositol 1,4,5-trisphosphate receptor expression, $\mathrm{Ca}(2+)$ signaling, and insulin secretion in the anx7(+/-) knockout mouse. Proc Natl Acad Sci USA 1999;96:13783-8.

39. Tanaka Y, Naruse I, Hongo T, et al. Extensive brain hemorrhage and embryonic lethality in a mouse null mutant of CREB-binding protein. Mech Dev 2000;95:133-45.

40. Tam SJ, Richmond DL, Kaminker JS, et al. Death receptors DR6 and TROY regulate brain vascular development. Dev Cell 2012;22:403-17.

41. Lyden D, Young AZ, Zagzag D, et al. Id1 and Id3 are required for neurogenesis, angiogenesis and vascularization of tumour xenografts. Nature 1999;401:670-7.

42. Zhu J, Motejlek K, Wang D, Zang K, Schmidt A, Reichardt LF. beta8 integrins are required for vascular morphogenesis in mouse embryos. Development 2002;129:2891-903.

43. Tran-Fadulu V, Pannu H, Kim DH, et al. Analysis of multigenerational families with thoracic aortic aneurysms and dissections due to TGFBR1 or TGFBR2 mutations. J Med Genet 2009;46:607-13.

44. Spyropoulos DD, Pharr PN, Lavenburg KR, et al. Hemorrhage, impaired hematopoiesis, and lethality in mouse embryos carrying a targeted disruption of the Flil transcription factor. Mol Cell Biol 2000;20:5643-52.

45. Benezra R, Rafii S, Lyden D. The Id proteins and angiogenesis. Oncogene 2001;20:8334-41.

46. Asano Y, Stawski L, Hant F, et al. Endothelial Fli1 deficiency impairs vascular homeostasis: a role in scleroderma vasculopathy. Am J Pathol 2010;176:1983-98.

47. Chabrier S, Husson B, Dinomais M, Landrieu P, Nguyen The Tich S. New insights (and new interrogations) in perinatal arterial ischemic stroke. Thromb Res 2011;127:13-22.

48. Göpel W, Gortner L, Kohlmann T, Schultz C, Möller J. Low prevalence of large intraventricular haemorrhage in very low birthweight infants carrying the factor V Leiden or prothrombin G20210A mutation. Acta Paediatr 2001;90:1021-4.

49. Olié V, Zhu T, Martinez I, Scarabin PY, Emmerich J. Sex-specific risk factors for recurrent venous thromboembolism. Thromb Res 2012;130:16-20.
50. Kloppenborg RP, Nederkoorn PJ, van der Graaf Y, Geerlings MI. Homocysteine and cerebral small vessel disease in patients with symptomatic atherosclerotic disease. The SMART-MR study. Atherosclerosis 2011;216:461-6.

51. Stuart S, Cox HC, Lea RA, Griffiths LR. The role of the MTHFR gene in migraine. Headache 2012;52:515-20.

52. Dodelson de Kremer R, Grosso C. Maternal mutation $677 \mathrm{C}>\mathrm{T}$ in the methylenetetrahydrofolate reductase gene associated with severe brain injury in offspring. Clin Genet 2005;67:69-80.

53. Harteman JC, Groenendaal F, Benders MJ, Huisman A, Blom HJ, de Vries LS. Role of thrombophilic factors in full-term infants with neonatal encephalopathy. Pediatr Res 2013;73:80-6.

54. Refsum H, Grindflek AW, Ueland PM, et al. Screening for serum total homocysteine in newborn children. Clin Chem 2004;50:1769-84.

55. Molloy AM, Mills JL, McPartlin J, Kirke PN, Scott JM, Daly S. Maternal and fetal plasma homocysteine concentrations at birth: the influence of folate, vitamin $\mathrm{B} 12$, and the 5,10-methylenetetrahydrofolate reductase 677C-> T variant. Am J Obstet Gynecol 2002;186:499-503.

56. Bauman ME, Cheung PY, Massicotte MP. Hemostasis and platelet dysfunction in asphyxiated neonates. J Pediatr 2011;158(Suppl):e35-9.

57. Chawla RK, Watson WH, Jones DP. Effect of hypoxia on hepatic DNA methylation and tRNA methyltransferase in rat: similarities to effects of methyl-deficient diets. J Cell Biochem 1996;61:72-80.

58. Ito K, Miwa N, Hagiwara K, et al. Regulation of methionine adenosyltransferase activity by the glutathione level in rat liver during ischemia-reperfusion. Surg Today 1999;29:1053-8.

59. Blaise S, Alberto JM, Nédélec E, et al. Mild neonatal hypoxia exacerbates the effects of vitamin-deficient diet on homocysteine metabolism in rats. Pediatr Res 2005;57:777-82.

60. Adén U, Lin A, Carlo W, et al.; Gene Targets for Intraventricular Hemorrhage Study Group. Candidate gene analysis: severe intraventricular hemorrhage in inborn preterm neonates. J Pediatr 2013;163:1503-1506.e1.

61. Volpe JJ. Intracranial hemorrhage: germinal matrix-intraventricular hemorrhage of the premature infant. In: Neurology of the Newborn, 5 edn. Philadelphia, PA: Saunders Elsevier; 2008:517-88.

62. Chen X, Threlkeld SW, Cummings EE, et al. Ischemia-reperfusion impairs blood-brain barrier function and alters tight junction protein expression in the ovine fetus. Neuroscience 2012;226:89-100.

63. Capuron L, Miller AH. Immune system to brain signaling: neuropsychopharmacological implications. Pharmacol Ther 2011;130:226-38.

64. Adén U, Favrais G, Plaisant F, et al. Systemic inflammation sensitizes the neonatal brain to excitotoxicity through a pro-/anti-inflammatory imbalance: key role of TNFalpha pathway and protection by etanercept. Brain Behav Immun 2010;24:747-58.

65. Sadowska GB, Threlkeld SW, Flangini A, Sharma S, Stonestreet BS. Ontogeny and the effects of in utero brain ischemia on interleukin-1ß and interleukin-6 protein expression in ovine cerebral cortex and white matter. Int J Dev Neurosci 2012;30:457-63.

66. Fan LW, Tien LT, Zheng B, Pang Y, Rhodes PG, Cai Z. Interleukin-1betainduced brain injury and neurobehavioral dysfunctions in juvenile rats can be attenuated by alpha-phenyl-n-tert-butyl-nitrone. Neuroscience 2010;168:240-52.

67. Ma Y, Matsuwaki T, Yamanouchi K, Nishihara M. Cyclooxygenase-2-related signaling in the hypothalamus plays differential roles in response to various acute stresses. Brain Res 2013;1508:23-33.

68. Cai Z, Pan ZL, Pang Y, Evans OB, Rhodes PG. Cytokine induction in fetal rat brains and brain injury in neonatal rats after maternal lipopolysaccharide administration. Pediatr Res 2000;47:64-72.

69. Bilbo SD, Biedenkapp JC, Der-Avakian A, Watkins LR, Rudy JW, Maier SF. Neonatal infection-induced memory impairment after lipopolysaccharide in adulthood is prevented via caspase-1 inhibition. J Neurosci 2005;25:8000-9.

70. Leviton A, Allred EN, Dammann O, et al. Systemic inflammation, intraventricular hemorrhage, and white matter injury. J Child Neurol 2012; e-pub ahead of print 30 October 2012.

71. Hwang IR, Kodama T, Kikuchi S, et al. Effect of interleukin 1 polymorphisms on gastric mucosal interleukin 1beta production in Helicobacter pylori infection. Gastroenterology 2002;123:1793-803. 
72. Wu YW, Croen LA, Torres AR, Van De Water J, Grether JK, Hsu NN. Interleukin-6 genotype and risk for cerebral palsy in term and near-term infants. Ann Neurol 2009;66:663-70.

73. Girotti M, Donegan JJ, Morilak DA. Influence of hypothalamic IL-6/gp130 receptor signaling on the HPA axis response to chronic stress. Psychoneuroendocrinology 2013;38:1158-69.

74. Harding D, Brull D, Humphries SE, Whitelaw A, Montgomery H, Marlow N. Variation in the interleukin-6 gene is associated with impaired cognitive development in children born prematurely: a preliminary study. Pediatr Res 2005;58:117-20.

75. Adcock K, Hedberg C, Loggins J, Kruger TE, Baier RJ. The TNF-alpha -308, MCP-1 -2518 and TGF-beta1 +915 polymorphisms are not associated with the development of chronic lung disease in very low birth weight infants. Genes Immun 2003;4:420-6.

76. de Vries LS, Koopman C, Groenendaal F, et al. COL4A1 mutation in two preterm siblings with antenatal onset of parenchymal hemorrhage. Ann Neurol 2009;65:12-8.

77. de Vries LS, Mancini GM. Intracerebral hemorrhage and COL4A1 and COL4A2 mutations, from fetal life into adulthood. Ann Neurol 2012;71:439-41.

78. Weng YC, Sonni A, Labelle-Dumais C, et al. COL4A1 mutations in patients with sporadic late-onset intracerebral hemorrhage. Ann Neurol 2012;71:470-7.

79. Bilguvar K, DiLuna ML, Bizzarro MJ, et al.; Pacifier and Breastfeeding Trial Group. COL4A1 mutation in preterm intraventricular hemorrhage. J Pediatr 2009;155:743-5.
80. Ko NU, Rajendran P, Kim H, et al. Endothelial nitric oxide synthase polymorphism $(-786 \mathrm{~T}->\mathrm{C})$ and increased risk of angiographic vasospasm after aneurysmal subarachnoid hemorrhage. Stroke 2008;39:1103-8.

81. Vannemreddy P, Notarianni C, Yanamandra K, Napper D, Bocchini J. Is an endothelial nitric oxide synthase gene mutation a risk factor in the origin of intraventricular hemorrhage? Neurosurg Focus 2010;28:E11.

82. Poggi C, Giusti B, Vestri A, Pasquini E, Abbate R, Dani C. Genetic polymorphisms of antioxidant enzymes in preterm infants. J Matern Fetal Neonatal Med 2012;25(Suppl 4):131-4.

83. Franz DN, Belousova E, Sparagana S, et al. Efficacy and safety of everolimus for subependymal giant cell astrocytomas associated with tuberous sclerosis complex (EXIST-1): a multicentre, randomised, placebo-controlled phase 3 trial. Lancet 2013;381:125-32.

84. Farooq F, Abadía-Molina F, MacKenzie D, et al. Celecoxib increases SMN and survival in a severe spinal muscular atrophy mouse model via p38 pathway activation. Hum Mol Genet 2013;22:3415-24.

85. Liew WK, Kang PB. Recent developments in the treatment of Duchenne muscular dystrophy and spinal muscular atrophy. Ther Adv Neurol Disord 2013;6:147-60.

86. Manolio TA, Chisholm RL, Ozenberger B, et al. Implementing genomic medicine in the clinic: the future is here. Genet Med 2013;15:258-67.

87. Bauer SC, Msall ME. Optimizing neurodevelopmental outcomes after prematurity: lessons in neuroprotection and early intervention. Minerva Pediatr 2010;62:485-97. 